\title{
Reconstruction of microstomia considering their functional status
}

\author{
Sae Hwi Ki ${ }^{1,2}$, \\ Gang Yeon Jo, \\ Jinmyung Yoon ${ }^{1}$, \\ Matthew Seung Suk Choi ${ }^{1}$ \\ ${ }^{1}$ Department of Plastic and \\ Reconstructive Surgery, Inha University \\ Hospital, Incheon; ${ }^{2}$ Department of \\ Plastic and Reconstructive Surgery, \\ Inha University School of Medicine, \\ Incheon, Korea
}

\begin{abstract}
Background: Microstomia is defined as a condition with a small sized-mouth that results in functional impairment such as difficulty with food intake, pronunciation, and poor oral hygiene and cosmetic problems. Several treatment methods for microstomia have been proposed. None of them are universally applicable. This study aims at analyzing the cases treated at our institution critically reviewing the pertinent literature.

Methods: The medical records of all microstomia patients treated in our hospital from November 2015 to April 2018 were reviewed retrospectively. Of these, all patients who received surgical treatment for microstomia were included in the study and analyzed for etiology, chief complaint, surgical method, and outcomes. The functional outcomes of mouth opening and intercommissure distance before and after the surgery were evaluated. The cosmetic results were assessed according to the patients' satisfaction.

Results: Five patients with microstomia were corrected. Two cases were due to scar contracture after chemical burn, two cases derived from repeated excision of skin cancer, and one patient suffered sequela of Stevens-Johnson syndrome. The following surgical methods were applied: one full-thickness skin graft on the buccal mucosa, three buccal mucosal advancement flaps after triangular excision of the mouth corner, and one local buccal mucosal flap. Mouth opening was increased by $6.0 \mathrm{~mm}$, and the intercommissure distance improved by $7.2 \mathrm{~mm}$ on average. Follow-up was 9.6 months (range, 5-14 months). Cosmetic assessment was as follows: two patients found the results excellent, three judged it as good.

Conclusion: Microstomia has several causes. In order to achieve optimal functional recovery and aesthetic improvement it is important to precisely evaluate the etiologic factors and the severity of the impairment and to carefully choose the appropriate surgical method.
\end{abstract}

Keywords: Microstomia / Mouth / Mucosa / Surgery

\section{INTRODUCTION}

The mouth is a cosmetically and functionally mobile organ located in the center of the face. Microstomia leads to a functional deterioration of the mouth that can result in problems with articulation, whistling, sucking, kissing, and salivary secretion

\section{Correspondence: Sae Hwi Ki}

Department of Plastic and Reconstructive Surgery, Inha University School of

Medicine, 27 Inhang-ro, Jung-gu, Incheon 22332, Korea

E-mail: mdki1967@gmail.com

Received May 29, 2020 / Revised June 16, 2020 / Accepted June 19, 2020 with drooling, poor oral hygiene due to dental care problems. In addition, microstomia causes cosmetic problems. On the other hand, the definition of microstomia is ambiguous because the image of the beauty of the mouth has changed over several decades and varies between the cultures and regions. Moreover, the functional deficit depends on the individual adaptation of the patient [1-5].

Congenital microstomia has rarely been reported [3,4]. The major causes of microstomia include contractures caused by thermal, electric, and chemical burns, as well as trauma and re- 
construction surgery after skin cancer ablation [2,5]. Several methods for the correction of microstomia have been reported. The majority of reports deal with certain specific cases of microstomia and and their treatment, but only few studies report on the treatment and outcomes according to the cause and different surgical methods. Therefore, this study analyzed cases of microstomia according to the cause, chief complaint, severity of microstomia, treatment methods, and outcomes.

\section{METHODS}

The medical records of all microstomia patients treated in our hospital from November 2015 to April 2018 were reviewed retrospectively. Of these, all patients who received surgical treatment for microstomia were included in the study. The causes that ked to microstomia, the symptoms, patients's chief complaints, the applied surgical methods, and functional and esthetic outcomes were analyzed.

Surgery had been considered for long-standing microstomia that did not improve after scar maturation. The patient was consulted to determine the chief complaint, functional deficit, and scarring at the corner of the mouth. The choice of surgical method to correct microstomia was determined by the patient's needs and symptoms, functional deficit, and the surgeon's preference.

The functional outcomes were evaluated based on the distance of mouth opening and the intercommissure distance before and 5 months after the surgery. The patients' satisfaction with the cosmetic outcome was evaluated according to the patients' satisfaction and classified as excellent, good, fair, not good, and poor. Statistical analysis was not conducted because of the small number of cases.

\section{RESULTS}

Fourteen patients with microstomia were reviewed. Nine patients, including those who had trauma or a skin cancer excision and simple reconstruction, did not undergo surgical treatment because of the improvement after conservative treatment. Surgical corrections were performed on five patients (two men and three women). The chief complaints of the patients were cosmetic, poor oral hygiene, difficulty of dental care, difficulty of mouth opening, and food intake restrictions. The mean age of the patients was 52.8 years (range, 22-65 years).

In two cases the scar contracture was caused by chemical burn with caustic soda, two cases acquired microstomia after repeat skin cancer excision, and one case resulted in scar contracture of the mouth corners due to mucosal inflammation after Stevens-Johnson syndrome. The patients with skin cancer suffered from microstomia appeared after recurrence of squamous cell carcinoma. These patients had a history of lip reconstruction with a local flap after the treatment of squamous cell carcinoma several years ago. Both patients with chemical burns caused by caustic soda developed symptoms without any treatment for microstomia. They had complaints of poor oral hygiene, difficult mouth opening and food intake, and a need for the treatment of dental caries (Table 1).

The following surgical correction methods were applied: mucosal excision and buccal mucosal advancement flap $(n=1)$, intraoral scar excision and full-thickness skin graft $(n=1)$, and

Table 1. List of cases

\begin{tabular}{|c|c|c|c|c|c|c|c|c|c|c|}
\hline $\begin{array}{r}\text { Case } \\
\text { No. }\end{array}$ & $\begin{array}{c}\text { Sex/age } \\
\text { (yr) }\end{array}$ & Cause & Past history & $\begin{array}{l}\text { Duration of } \\
\text { microstomia }\end{array}$ & Chief complain & $\begin{array}{l}\text { Preoperative } \\
\text { finding (mm) }\end{array}$ & Operation method & $\begin{array}{l}\text { Postoperative } \\
\text { result (mm) }\end{array}$ & $\begin{array}{l}\mathrm{FU} \\
\text { period }\end{array}$ & $\begin{array}{l}\text { Patient } \\
\text { satisfaction }\end{array}$ \\
\hline 1 & $F / 22$ & $\begin{array}{l}\text { Stevens-Johnson } \\
\text { syndrome }\end{array}$ & None & $2 \mathrm{mo}$ & $\begin{array}{l}\text { Aesthetic } \\
\text { problem }\end{array}$ & $\begin{array}{l}\text { ID: } 28 \\
\text { ICD: } 37\end{array}$ & Local flap & $\begin{array}{l}\text { ID: } 35 \\
\text { ICD: } 41\end{array}$ & $12 \mathrm{mo}$ & Excellent \\
\hline 2 & $F / 65$ & Caustic soda & Hypertension & $62 \mathrm{yr}$ & $\begin{array}{l}\text { Dental care } \\
\text { inability }\end{array}$ & $\begin{array}{l}\text { ID: } 25 \\
\text { ICD: } 30\end{array}$ & $\begin{array}{l}\text { Bilateral triangular excision } \\
\text { and buccal mucosal } \\
\text { advancement flap }\end{array}$ & $\begin{array}{l}\text { ID: } 36 \\
\text { ICD: } 46\end{array}$ & $14 \mathrm{mo}$ & Good \\
\hline 3 & $\mathrm{M} / 50$ & $\begin{array}{l}\text { SCC excision } \\
\text { and local flap } \\
\text { of lower lip }\end{array}$ & $\begin{array}{l}\text { SCC excision and closure } \\
\text { (12 yr ago), SCC recurrence } \\
\text { and Estlander flap (2 yr ago) }\end{array}$ & $2 \mathrm{yr}$ & $\begin{array}{l}\text { Difficulty of food } \\
\text { intake }\end{array}$ & $\begin{array}{l}\text { ID: } 36 \\
\text { ICD: } 35\end{array}$ & $\begin{array}{l}\text { Unilateral triangular excision } \\
\text { and buccal mucosal } \\
\text { advancement flap }\end{array}$ & $\begin{array}{l}\text { ID: } 37 \\
\text { ICD: } 43\end{array}$ & $9 \mathrm{mo}$ & Good \\
\hline 4 & $F / 54$ & Caustic soda & $\begin{array}{l}\text { Esophagus reconstruction } \\
\text { with large colon, } \\
\text { tracheostomy due to } \\
\text { caustic soda injury } \\
\text { (15 yr ago) }\end{array}$ & $15 \mathrm{yr}$ & $\begin{array}{l}\text { Difficulty of } \\
\text { mouth } \\
\text { opening, } \\
\text { dental care } \\
\text { inability }\end{array}$ & $\begin{array}{l}\text { ID: } 21 \\
\text { ICD: } 36\end{array}$ & $\begin{array}{l}\text { Scar release and FTSG on } \\
\text { buccal mucosa }\end{array}$ & $\begin{array}{l}\text { ID: } 26 \\
\text { ICD: } 36\end{array}$ & $8 \mathrm{mo}$ & Excellent \\
\hline 5 & $M / 65$ & $\begin{array}{l}\text { SCC excision } \\
\text { and local flap } \\
\text { of lower lip }\end{array}$ & $\begin{array}{l}\text { SCC excision and Estlander } \\
\text { flap (1 yr ago) }\end{array}$ & $6 \mathrm{mo}$ & $\begin{array}{l}\text { Dental care } \\
\text { inability }\end{array}$ & $\begin{array}{l}\text { ID: } 22 \\
\text { ICD: } 30\end{array}$ & $\begin{array}{l}\text { Bilateral triangular excision } \\
\text { and buccal mucosal } \\
\text { advancement flap }\end{array}$ & $\begin{array}{l}\text { ID: } 28 \\
\text { ICD: } 36\end{array}$ & $5 \mathrm{mo}$ & Good \\
\hline
\end{tabular}

FU, follow-up; F, female; M, male; ID, interlabial distance; ICD, intercommissure distance; SCC, squamous cell carcinoma; FTSG, full-thickness skin graft.

a)Patient satisfaction: excellent, good, fair, not good, poor. 

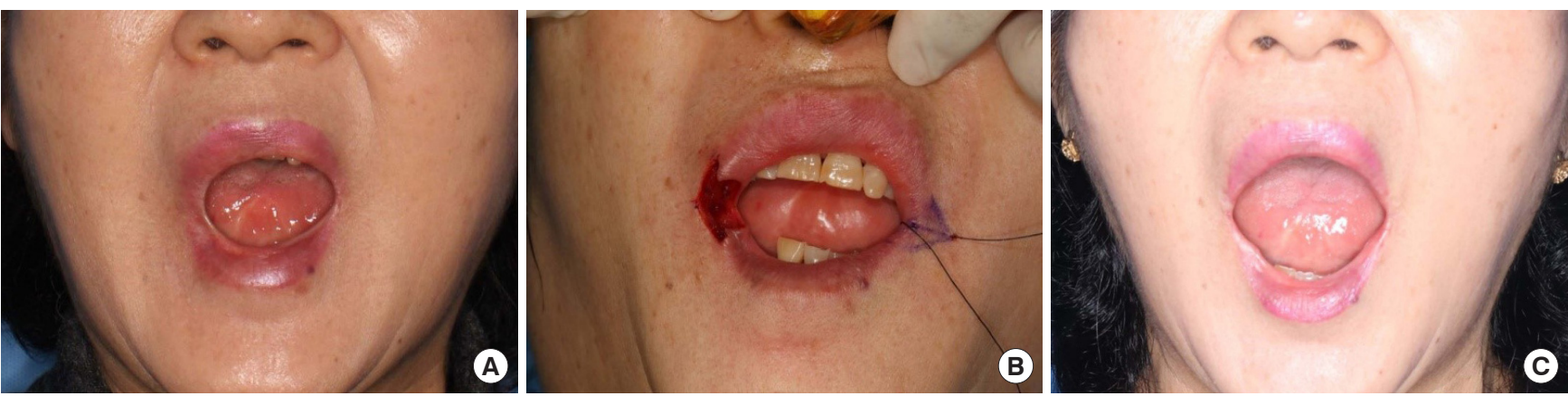

Fig. 1. Microstomia with perioral scar contracture including buccal mucosa due to caustic soda. (A) Preoperative photograph (mouth opening: $25 \mathrm{~mm}$, intercommissure distance: $30 \mathrm{~mm}$ ). (B) Preoperative design: triangular excision of a mouth corner intraoperative photograph-excision of the orbicularis oculi muscle and intraoral buccal mucosa advancement flap. (C) Postoperative improvement of the opening of the mouth (mouth opening: $36 \mathrm{~mm}$, intercommissure distance: $46 \mathrm{~mm}$ ).
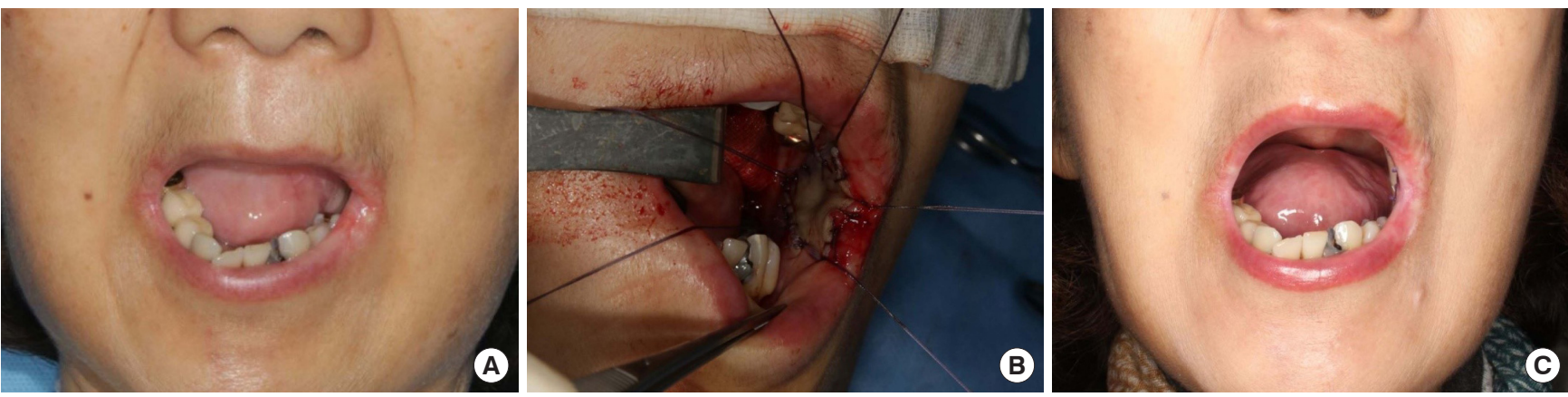

Fig. 2. Microstomia with perioral scar contracture due to caustic soda. Malnutrition and dental caries were found. The temporomandibular joints were mobile. (A) Preoperative photograph (mouth opening: $21 \mathrm{~mm}$, intercommissure distance: $36 \mathrm{~mm}$ ). (B) Scar release and full-thickness skin graft $(4.5 \times 2 \mathrm{~cm}$ sized) on the left buccal mucosa. (C) Postoperative improvement of the opening of the mouth (mouth opening: 26 $\mathrm{mm}$, intercommissure distance: $36 \mathrm{~mm}$ ).

three cases of triangular excision of mouth corner that was covered with a buccal mucosal advancement flap $(\mathrm{n}=3)$ (Figs. 1, 2). All cases healed uneventfully. Both patients with microstomia after repeat skin cancer excision, developed temporary drooling of saliva that was caused by oral incompetence, which resolved after 6 months. Patient satisfaction with the cosmetic outcomes was as follows: two found the result excellent, and three good. The follow-up period was 5 to 14 months (mean, 9.6 months). The distance of mouth opening increased by an average of 6.0 $\mathrm{mm}$ from $21-36 \mathrm{~mm}$ (mean, $26.5 \mathrm{~mm}$ ) to $26-37 \mathrm{~mm}$ (mean, $33 \mathrm{~mm}$ ) after surgery. The intercommissure distance was increased by an average of $7.2 \mathrm{~mm}$ from $30-37 \mathrm{~mm}$ (mean, 34.5 $\mathrm{mm}$ ) to $36-46 \mathrm{~mm}$ (mean, $41.5 \mathrm{~mm}$ ) after surgery.

\section{DISCUSSION}

Even though we can define the ideal size of the mouth as equidistant to the pupillary distance or 1.5 times the alar width [6], it is difficult to find a sharp definition for microstomia because the citeria for a what can be considered a beautiful mouth var- ies depending on the culture, geographic region, and historic period. Moreover, the mouth size varies significantly among healthy individuals. Therefore, the diagnosis of microstomia depends on the presence of a functional deficit or the patient's personal perception.

With the exception of epidermolysis Bullosa, Freeman-Sheldon syndrome, and Kawasaki disease microstomia rarely has a congenital origin $[3,5]$. The major causes of microstomia are chemical burn with caustic soda material, trauma, and skin cancer excision [1-5,7-9]. If the mouth sustains trauma or a chemical burn, the size of the oral opening can become smaller and dysfunction of mouth opening can occur. The limitation of mouth opening depends on the amount of intraoral and perioral scar contracture. The severity of microstomia varies according to the degree and depth of injury of the intraoral and perioral area [7]. Depending on the severity of microstomia, the patient can have difficulty in pronunciation, speech, swallowing, food intake, oral hygiene, and aesthetic impairment [15,7-9].

Treatment of microstomia is always challenging. Conservative 
treatment and non-surgical treatments, such as physical therapy, various dentures, and prosthetics, are used to prevent and to alleviate microstomia $[7,8]$. Mild microstomia can be corrected with Z-plasty and skin grafts, but severe cases require complete excision of the scar and more complex reconstructions, sometimes even in a staged manner. Dieffenbach described surgical treatment using superior, inferior, and lateral mucosal advanced flap after scar excision of the mouth corner in 1831. Since then, several modifications of this original method have been described by Converse, Friedlander, and Kazanjian [1,2,4,5,9]. Many authors have introduced other surgical methods, such as vermilion advancement and Z-plasty, Y-shaped incision and mucosal trapezoid flap, fishtail flap, bipediculovermilion transposition flap, composite auriculo lobule graft, and tongue flap [8,10-13]. In serious cases even correction with a free flap may be necessary.

Different surgical methods were performed on various cases depending on the degree of involvement: scarring of mucosa only, intraoral buccal mucosa, involvement of orbicularis oris muscle, or full-thickness defect of the lip. The webbing of the mouth corner after Stevens-Johnson syndrome was corrected with a mucosal excision and buccal mucosal advancement flap. In cases of chemical burns with scar contracture limited to the buccal mucosa, where the temporomandibular joint (TMJ) was mobile, reconstruction can be carried out by excision of the intraoral scar and full-thickness skin graft were performed on the without correction of the mouth corner. In our series the cases of chemical burns and of repeated skin cancer excision, the severe pathologic lesion was located in the mouth corner with shoratage of both skin and intraoral mucosa. Scar release was performed by triangular excision of both skin and orbicularis oris of the mouth corner and covered with a buccal mucosal advancement flap. After surgery, all patients showed improvement in the intercommissure distance and mouth opening, oral intake of food, dental care, oral hygiene, and functional recovery of the mouth. Two patients, who were corrected with a triangular excision of the mouth corner and buccal advancement flap, showed temporary drooling of saliva, but the symptoms improved after 6 months.

Based on our experience the following is recommended for the treatment of microstomia: In the early stage, we recommend conservative treatment methods such as, oral splint appliance, physical therapy, and exercise the patient adapts to the microstomia and scar maturation is complete. When functional limitation of the mouth opening remains after proper conservative treatment, surgery is the method of choice. Selection of the appropriate surgical method is important for correcting microstomia and should be done according to the severity of the microstomia. For mild cases of microstomia there are many methods available: Z-plasty, W-plasty, local mucosal advancement flap, mucosal transposition flap, split thickness skin graft, and full-thickness skin or mucosal graft. When choosing the surgical method for mild cases the desire of the patient and the surgeon's preference can play a role. In severe microsomia, the conditions of the patient is the main factor to consider. It is important to evaluate the motion of the TMJ before surgery. If there is limitation of TMJ motion, functional recovery of the mouth opening will be poor even after perfect correction of the scar contracture in the mouth corner. Due to the limitation of mouth opening in microstomia patients, it is difficult to preoperatively check the range of motion of the TMJ. Thorough physical examination of the TMJ may be need to supplemented by computerized tomography and magnetic resonance imaging.

If the TMJ motion is not limited, the surgical method is chosen solely according to the severity of microstomia and depending on where the scar contracture is located and on its amount. When the scar contracture is limited to the mouth corner, we use triangular skin excision and mucosal advancement flap. However, when scar contracture is located in the buccal mucosa or the surrounding skin of mouth corner, it is difficult to use an advancement flap of the skin or the mucosa. For improvement of the contracture in these cases, both mucosal and skin graft are necessary. In severe cases, free flap may be required. Since all surgical procedures also affect the cosmetic outcome, the patient's desire should be taken into consideration.

The limitations of the present study are the small number of cases. The pool was too small for analysis of the pathophysiology of microstomia, statistical analysis the outcomes and causes. More cases and studies from other institutions will be needed to establish a scientific basis the choice of surgical correction of microstomia.

The selection of appropriate surgical method according to the cause and severity of microstomia is important for improving the functional recovery, aesthetic outcomes, and postoperative satisfaction of microstomia patients.

\section{NOTES}

\section{Conflict of interest}

No potential conflict of interest relevant to this article was reported.

\section{Ethical approval}

The study was approved by the Institutional Review Board of Inha University Hospital (IRB No. 2020-05-011) and per- 
formed in accordance with the principles of the Declaration of Helsinki. Written informed consents were obtained.

\section{Patient consent}

The patients provided written informed consent for the publication and the use of their images.

\section{ORCID}

Sae Hwi Ki

https://orcid.org/0000-0001-9194-9681

Gang Yeon Jo

https://orcid.org/0000-0003-3951-9830

Jinmyung Yoon

https://orcid.org/0000-0002-8129-0753

Matthew Seung Suk Choi

https://orcid.org/0000-0002-7849-1861

\section{REFERENCES}

1. Kazanjian VH, Roopenian A. The treatment of lip deformities resulting from electric burns. Am J Surg 1954;88:884-90.

2. Egeland B, More S, Buchman SR, Cederna PS. Management of difficult pediatric facial burns: reconstruction of burn-related lower eyelid ectropion and perioral contractures. J Craniofac Surg 2008;19:960-9.

3. Cakan M, Aktay Ayaz N, Keskindemirci G, Onan SH, Akoz Saydam F. A case of Kawasaki disease with severe lip and oral mucosa involvement complicated with microstomia and corrected with surgery. Arch Rheumatol 2017;33:238-40.

4. Zweifel CJ, Guggenheim M, Jandali AR, Altintas MA, Kunzi W, Giovanoli P. Management of microstomia in adult burn pa- tients revisited. J Plast Reconstr Aesthet Surg 2010;63:e351-7.

5. Mordjikian E. Severe microstomia due to burn by caustic soda. Burns 2002;28:802-5.

6. Lehocky B. Anthropometry and cephalometric facial analysis. In: Mathes SI, editor. Plastic surgery. 2nd ed. Philadelphia: Saunders; 2006. p. 1-30.

7. Conine TA, Carlow DL, Stevenson-Moore P. Dynamic orthoses for the management of microstomia. J Rehabil Res Dev 1987;24:43-8.

8. Holt GR, Parel S, Richardson DS, Kittle PE. The prosthetic management of oral commissure burns. Laryngoscope 1982; 92:407-11.

9. Converse JM. Techniques for the repair of defects of the lips and cheeks. In: Converse JM, editor. Reconstructive plastic surgery. 2nd ed. Philadelphia: Saunders; 1977. p. 1544-94.

10. Grishkevich VM. Post-burn microstomia: anatomy and elimination with trapeze-flap plasty. Burns 2011;37:484-9.

11. Monteiro DI, Horta R, Silva P, Amarante JM, Silva A. A simple "fishtail flap" for surgical correction of microstomia. J Craniofac Surg 2011;22:2292-4.

12. Donelan MB. Reconstruction of electrical burns of the oral commissure with a ventral tongue flap. Plast Reconstr Surg 1995; 95:1155-64.

13. Ayhan M, Aytug Z, Deren O, Karantinaci B, Gorgu M. An alternative treatment for postburn microstomia treatment: composite auricular lobule graft for oral comissure reconstruction. Burns 2006;32:380-4 